\title{
Nexus between Social Capital and Firm Performance: A Critical Literature Review and Research Agenda
}

\author{
Kaberia S. Kanini ${ }^{1} \&$ Stephen M. A. Muathe ${ }^{1}$ \\ ${ }^{1}$ School of Business, Kenyatta University, Kenya \\ Correspondence: Kaberia S. Kanini, School of Business, Kenyatta University, Kenya. E-mail: \\ sallyolweny@gmail.com
}

Received: April 29, 2019

Accepted: May 20, 2019

Online Published: July 7, 2019

doi:10.5539/ijbm.v14n8p70

URL: https://doi.org/10.5539/ijbm.v14n8p70

\begin{abstract}
Given the importance of social capital in entrepreneurial success and growth, understanding how it can be exploited for optimal performance of the venture becomes critical. While the Government of Kenya, in recognition of the importance of entrepreneurial ventures in driving the economy, has put in both structural and affirmative measures towards enhancement of social capital and support for entrepreneurs, performance of these businesses still remains significantly low. The objectives of this study were to discuss the key constructs, variables and perspectives underlying the conceptualization of social capital and performance, and the arising controversies. Additionally, the study sought to discuss key methodological issues emerging from existing empirical studies, highlight critical knowledge gaps emanating from critical review of the literature and suggest a robust conceptual framework to guide a further study that would address the highlighted knowledge gaps. This study is anchored on the social capital theory which strongly considers social capital as an essential form of capital; one that no business can ignore and expect to survive or thrive. Other supporting theories include the contingency theory, economic theory, anthropological theory and innovation theories. Among the major gaps identified by this study include methodological gaps; most studies reviewed used descriptive design which is known to be the weakest in establishing cause and effect relationships. Some of the studies had very small sample sizes, known to potentially increase errors. Other gaps include contextual gaps; most of the studies considered established businesses where operations tend to be more standardized and innovation is adequately funded, unlike the low income areas where resources are often limited. Conceptual gaps were identified among studies that used direct relationships. For a broader and deeper appreciation of the relationship between social capital and performance, this study recommends conceptualization of a future study whereby the mediating effect of innovation and the moderating effect of operating business environment are considered, preferably within a low income area with less established / informal businesses within the service sector.
\end{abstract}

Keywords: social capital, firm performance, business operating environment, innovation, small and medium enterprises (SMEs)

\section{Introduction}

Social capital has emerged as a multi-faceted element that has become relevant among developed and developing countries alike (World Bank, 2011). It is considered as comprising of a reserve of social norms, standards, ideals, attitudes, trusts, responsibilities, connections, associates, public engagements, information flows, as well as bodies that promote co-operation and collaboration towards shared gains while enhancing socio-economic advancement of the actors. Granovetter (1985) opines that most economic attitudes and actions are entrenched in the social connections of the actors involved.

Social capital depicts the linkage and significance of both knowledge and networks - it is the 'who you know' that would influence the 'what you will know', implying the information and knowledge acquired through one's social circles (Lowik, van Rossum, Kraaijenbrink, \& Groen, 2012). While knowledge is a critical component without which innovation may not take place, (Lowik et. al., 2012), it is transmitted through interactions among connectors (Kanter, 1988 in Björk, 2011). The capacity to innovate is considered as directly related to a venture's ability to apply its resources and knowledge; Mahr (2014), hence researchers place emphasis on the role of individual manpower in enhancing innovation capacity; the expertise, abilities and experience introduced to the organization by scientists and engineers largely catalyses firm innovation (Romijin, 2002). Ultimately and 
as evidenced by Grossman and Helpman (1991), and Aghion and Howitt (1992), the higher the output of innovative productions, the higher the per capita income; which is an economic indicator of firm growth and performance. This common ground on the importance of social capital has thus made it critical for entrepreneurs, development economists and policy makers alike to want to appreciate how it can be formed, measured, applied and exploited for optimal gains.

Firms with higher social capital (SC) are better placed to achieve their objectives under low environmental turbulence. Under high environmental turbulence, nonetheless, social capital has been found to contribute positively towards the firm's performance (Tang et al., 2010; Chawla et al., 2012).Despite of and in addition to the challenge of limited resources, ventures must thus strive for flexibility that will allow them to respond to the anticipated and unforeseen environmental instability (Nunéz \& Lynn, 2012; Coad et al., 2013). The promise of social capital, therefore, as a centre-piece and anchor that influences information flow and innovation while controlling the business operating environment for optimal firm performance, makes it not only an inimitable asset for the entrepreneur, but also makes further research and study of social capital both exciting and revolutionary.

\subsection{Statement of the Problem}

The Government of Kenya through Sessional Paper no. 2 (Republic of Kenya, March 2014) which seeks to address the social security challenges experienced by Kenyan people aptly highlights the importance of social capital. Despite these reforms and enforcement measures, business performance has remained low. As per the Sessional Paper No. 2 on development of micro and small enterprises for wealth and employment creation for poverty reduction, (Government of Kenya, 2005), SMEs in Kenya are key in poverty eradication, yet they continue to reveal a worryingly high failure rate; with most start-up businesses collapsing before their third anniversary.

Tantardini and Kroll (2015) argue that organizational social capital is a very significant tool for performance management, yet it is also one of the most disregarded. Previous studies such as Ismail et. al., (2014) and Subrahmanya (2011), have studied the linkage between social capital and firm performance among established business settings such as manufacturing, auto and electronics firms respectively, hence there is need to focus on the less formal businesses which are characterized by limited resources and non-documented measures of performance. Other studies conducted by Kiprotich (2014) studied social capital and growth of SMEs in Nairobi County, Obonyo (2017) (social capital and growth of SMEs in Kenya) and Mbizi et al. (2013) have all applied descriptive design, which has been known to be the weakest in studies that seek to test predictions on cause and effect relationships among variables; descriptive design largely describes variables rather than test the relationship between the variables.

Obonyo (2017) studied the direct relationship but did not consider any mediating or moderating variables. Given that business do not exist in a vacuum, downplaying or failing to consider the moderating and mediating variables is likely to yield inaccurate or weak findings. Some authors such as Rosli and Sidek (2013) have studied the mediating effect of innovation on the performance of SMEs in Malaysia, Ismail et al. (2014) studied the role of innovation on SMEs in the manufacturing and service sectors in Malaysia. Others such as Pratono and Mahmood (2016) studied the entrepreneurial ecosystem and sought to establish the moderating effect of environmental turbulence and mediating effect of market capability in the connection between entrepreneurial orientation (EO) and firm performance. None so far, however, have studied the combination of innovation and operating business environment as mediating and moderating effects respectively, on social capital and firm performance.

Pratono and Mahmood (2016) further applied quantitative technique with cross-sectional data design, which has been known to limit the study by giving barely a snapshot observation that may not be relied upon. It is on this basis that this study was conceptualized to address the gaps by seeking to understand and critique earlier work on this matter, with a view to provide further insights and contribute to the knowledge for policy makers and stakeholders to enhance the resources available and yield better outcomes. Evaluating the role of social capital in entrepreneurship becomes even more pertinent, given that the ultimate desire of every entrepreneur, financier and stakeholder is to optimize the factors that positively affect performance of the venture.

\subsection{Objectives of the Study}

The objectives of this study were to:

i. Discuss the key constructs, variables and perspectives underlying the conceptualization of social capital and performance, and the arising controversies. 
ii. Discuss the key methodological issues emerging from existing empirical studies on social capital and performance.

iii. Highlight critical knowledge gaps emanating from the critical review of the literature in social capital and performance.

iv. Suggest a robust conceptual framework to guide a further study to address the key highlighted knowledge gaps.

\section{Theoretical and Literature Review}

This chapter builds on the previous chapter and highlights the conceptualization of the elements used in the study. It underpins the theoretical bases of the constructs with a view to establishing relevant theoretical framework and gaps. The conceptual review is organised in terms of the constructs, which include social capital, innovation, operating business environment and performance. Review will focus on studies that have been carried out on the linkage between social capital and firm performance. It further seeks to review studies that have used the business operating environment as a moderating variable, as well as those that may have considered the mediating effect of innovation on the performance of the business. This forms the basis on how the concepts / constructs are measured in this study.

\subsection{Review of the Relevant Theories}

This section highlights the underpinning theories with a view to establishing relevant theoretical framework and gaps.

\subsubsection{Social Capital theory}

The theory of social capital is anchored on the concept of norms, trust, beliefs and semi or unofficial interactions, and argues that social interactions are precious resources. Some researchers highlighted resemblance of social capital theory to ethical philosophy on the basis that the production procedure is driven by norms and objectives (Favell, 1993). Due to the seeming ease with which these resources are acquired, some scholars have criticized social capital on the basis that investing in social capital seems to happen without any opportunity costs for the beneficiary, unlike investment in other capitals. Woolcock, (1998) reacts by observing that while individual members may not necessarily place any direct investment into social capital as they would in other forms of capital, they repeatedly subject themselves to deliberate choices and have to consciously decide on which clubs to join certain clubs, or go out of their way do favors for certain persons, and strive to maintain relationships; in anticipation of future benefits. These deliberate actions, therefore, qualify in some aspects to be opportunity costs.

Networks may act as catalysts for idea generation, as well as alternative sources of investment capital. Confidential information will often flow through somewhat restricted networks, some of which could only be accessed through social interactions. It is the entrepreneur who is able to recognize and seize such opportunities, consciously or subconsciously, that will emerge as a major beneficiary of their social interactions. A model study conducted by Granovetter (1973) concluded that weak ties are better than strong ties in helping the connectors' access to opportunity-based information. The author portends that close-up ties are often laced with unnecessary information, e.g. during interaction among friends or family, the participants are often few and may repeatedly discuss the same experiences and information.

However, if an individual establishes weak ties with hundreds of persons in various networks, they will likely gain access to information that may not have flown through their closed ties. According to Burt (1992), there is increased benefit for those who strive to bridge "structural holes' that occur as a result of lack of interactions between larger social connections. The author further accentuates that it is not the quantity of ties that counts, but the level of necessity of the ties. For example, a person who maintains links with two social groups that have had no previous links stands a better chance to learn and transfer information between the two groups, that if there were more members already connecting the two groups. Additionally, if several links were necessary for the linkage of the two groups, then the sole direct link stands to gain more; as in the case of first mover advantage.

According to Adler and Kwon (2000), when analyzing social networks as a component of social capital, one must consider three elements namely the opportunity i.e. the varied dealings likely to materialize from shared ties, the impetus that consists of trust as well as the necessary drive to proceed, and the ability i.e. the real ability of individual contacts to yield the desired outcome. Critics of this theory view it as potentially leading to unscrupulous practice recommendations, as it seems to advocate for the active creation of weak ties at the expense of strong ties. Further, certain implications about how a good set of weak ties are obtained may have some "divide and conquer" or Machiavellian characteristics. There is need, therefore, to carry out further 
research on the effect of strength / weakness of ties in social networks on the resultant social capital amongst the members.

\subsubsection{Anthropological Theory of Entrepreneurship}

The sociological (also referred to as anthropological) theories centre their justification on the varied social contexts present and which catalyze the opportunities so exploited by entrepreneurs. They argue that the societal / religious beliefs, customs, taboos and practices have an indispensable influence of the behavior of individuals within the said society; including the entrepreneur's behavior and actions. The entrepreneur is thus viewed as a role performer who enacts the script as per societal expectations. The anthropological school of thought thus places entrepreneurship within the context of culture and examines how cultural forces such as attitudes, beliefs and practices shape the perception and behavior of the entrepreneur.

Heilbrunn (2004) points out two major theoretical perspectives that would help us better appreciate the distinction that exists between male and female entrepreneurs. The Social Feminism theory portends that men and women in entrepreneurship assume or are compelled by nature to adopt different business approaches, leading to differences in effectiveness and efficiency (of the venture). The second perspective is the theory of Liberal Feminism that considers both genders to be equal, yet goes on to highlight that male entrepreneurs thrive more than their female counterparts when in business. This variation is caused by gender-related aspects such as blatant biases within the economic market, and the female-specific pressure for balance between nurturing and time or resources spent on the business etc.

\subsubsection{Economic Theory of Entrepreneurship}

Alfred Marshall's Theory of Entrepreneurship (1890) considered four key factors of production as land, labor, capital and organization. Entrepreneurship was then pinpointed as the motivating factor that harnesses convergence of the other four factors. The scholar observes that the among the key characteristics of a triumphant entrepreneur include an in-depth understanding of the industry, excellent leadership skills and foresight around the dynamic precepts of demand and supply, as well as entrepreneur's decisive willingness to act on such risky foresights. However, he further argues that the successful entrepreneur is not necessarily one who possesses the said skills, but one who is able to exploit and contain the turbulences arising from the economic conditions or environment within which they carry out their ventures.

Subsequently, many economists have opined that Marshall's theory should be modified to include entrepreneurship as the fourth factor in lieu of organization; which would then make entrepreneurship the coordinating factor for the other three factors. All economic theories present explanations for entrepreneurship that heavily focus on the existing economic conditions and the opportunities they create. These economic incentives include sources of funding and raw materials, taxation policies, infrastructure development, access to information about investment and market conditions etc. It is at this point (sources of funding) that social networks become a critical factor in start-up funding of entrepreneurial ventures.

\subsubsection{Resource Based View}

Resource-based view (RBV) discusses the entrepreneur's capacity to transform and apply valuable resources to attain goals; these resources may be tangible or intangible. According to Penrose (1959), the classical theory of the RBV portends that organizations must take charge of more resources in order to attain their objectives. The referenced resources comprise of material properties, competencies and information (Barney, 1991). Resources consist of both tangible and intangible assets. As an intangible resource, social capital (SC) becomes pivotal in boosting the SMEs' performance (Sciascia, Mazzola, \& Chirico, 2012). Porter (1990) further posits that the RBV indicates that organizations that possess precious, unique and irreplaceable resources are better placed to attain a competitive edge.

The RBV further posits that firms that consciously remain innovative in the provision of higher value to customers often gain sustained competitive edge over the competition (Gupta \& Malhotra, 2013). It is the agile capacity of ventures to handle external shocks that is critical to the enterprise's performance and ultimate survival.

\subsubsection{Schumpeterian Theory of Innovation}

Schumpeter (1994) viewed innovation as the entrepreneur's distinctive role. Highlighting economic performance as a following a rather natural and mechanical process which is rarely consistent, entrepreneurship takes the role improving the way of doing things, and thus innovation becomes indispensable in achieving this mission. It is no wonder then that the entrepreneur who drives continuous innovation gains more in the short term and ling term. Despite the focus by economists on exterior pressure applied on the firm, Schumpeter is persuaded that 
transformation can take an inside-out approach to create a business cycle of sorts, and eventually yield holistic transformation of the entire economy. This scholar hence fronts a new factor of production whereby the entrepreneur is charged with recreating new and improved mixtures from the resources already in place; a process that drives innovation.

This will result in introduction of new commodities or services to the market, enhancement of production methods within the firm, creation of new sales segments and discovery of new or better raw materials, not to mention industry streamlining for better efficiency and greater gain, as posited by Casson et al., (2002). According to Schumpeter (1994), the entrepreneur is driven by an insatiable need for control and autonomy, the determination to achieve more as well as the fulfillment of achieving it, observes Swedberg (2000). The author conceptualizes 'creative destruction' as a method of change that results from yet also leads to innovation through ceaseless destruction of old ways of doing things towards creative new ways. When pursued continuously, this process yields steady innovation, as observed by Aghion and Howitt(1992).

In a capitalist system, the value placed on an entrepreneur comes from the realization that it is the entrepreneurial persistent innovation that leads to economic disruption and growth. It is the entrepreneur who bears the choice, to passively adapt to exterior demands on the business, yet may opt to proactively destroy the equilibrium from within through invention new products, process reengineering or takes actions challenging the habitual structures and activities, as argued by Andersen (2004) and Drejer (2004). The Schumpeterian Theory is critical in informing the entrepreneur's decisions in such cases, where power and leadership is sought and practiced amongst existing networks. This theory therefore links with social networks of the entrepreneur, in that one cannot seek or yield power alone but only within human networks.

\subsubsection{Contingency Theory}

The firm's capacity to promptly handle the business environment is largely dependent on the firm's knowledge management system in place, which requires that firms continually engage in consumer intelligence management. The information so obtained helps inform the firm's change strategy, which is a major management tool at the firm's disposal to proactively help the firm in countering the variety and intensity of environmental turbulence that come their way (Lowe, Lowe, \& Lynch, 2010). Firms can therefore acquire knowledge through continuously assessing their business environment they face, and subsequently reviewing their strategies to counter every angle and altitude of environmental turbulence (Johannesson \& Palona, 2010).

Contingency effects include environmental turbulence that represents the antagonism of the exterior business atmosphere, and which often translates to insecurity for affected ventures (Zhang \& Duan, 2010). Environmental turbulence is known to shock SMEs, hence it is imperative that the firms apply a vigilant blend of contingencies and decisioning structures that facilitate optimal venture performance (Chung et al., 2012). As a strategy for contingency, firms therefore put in place change management strategies that can be activated as and when the need arises.

\subsubsection{Summary of Theories}

Table 1. Summary of theoretical review

\begin{tabular}{|c|c|c|c|}
\hline Theory & Promoters & Argument & Relevance \\
\hline Social Capital & Granovetter (1973) & $\begin{array}{l}\text { The value of venture founders' network } \\
\text { resources which catalyze idea generation, } \\
\text { funding and growth of the venture. }\end{array}$ & $\begin{array}{l}\text { Social capital is at the core of this theory, } \\
\text { which highly values social networks. }\end{array}$ \\
\hline Economic theory & Alfred Marshall (1890) & $\begin{array}{l}\text { Land, labor, capital and organization are } \\
\text { the four factors of production; } \\
\text { entrepreneurship is the driving force that } \\
\text { convenes these four factors. }\end{array}$ & $\begin{array}{l}\text { Social networks provide a critical source of } \\
\text { funding especially for start-ups }\end{array}$ \\
\hline $\begin{array}{l}\text { Anthropological } \\
\text { Sociological }\end{array}$ & $\begin{array}{l}\text { Karl Max, Weber, } \\
\text { Putnam }\end{array}$ & $\begin{array}{l}\text { The entrepreneur is thus viewed as a role } \\
\text { performer who enacts the script as per } \\
\text { societal expectations. }\end{array}$ & $\begin{array}{l}\text { Social context and networks present } \\
\text { opportunities and catalyze entrepreneurship }\end{array}$ \\
\hline Innovation & Schumpeter (1984) & $\begin{array}{l}\text { The entrepreneur introduces new mixtures } \\
\text { of already existing resources and drives, } \\
\text { leading to innovation through "creative } \\
\text { destruction". }\end{array}$ & $\begin{array}{l}\text { Innovation is influenced by social interactions } \\
\text { with people and processes; their needs and } \\
\text { demands. }\end{array}$ \\
\hline Resource Based View & Jay Barney -1991 & $\begin{array}{l}\text { Competitive advantage is gained through } \\
\text { an enterprise's effective use of physical } \\
\text { and subtle resources and possessions. }\end{array}$ & $\begin{array}{l}\text { The entrepreneur's Social capital provides one } \\
\text { of these unique resources that create } \\
\text { competitive advantage for the firm }\end{array}$ \\
\hline Contingency theory & Fred Fiedler, mid 1960s & $\begin{array}{l}\text { Proposes that a firm's performance is } \\
\text { determined by the fit between its } \\
\text { resources, structure and strategies on one } \\
\text { hand, and the external environmental } \\
\text { conditions on the other hand (such as } \\
\text { political, economic, social and } \\
\text { technological). }\end{array}$ & $\begin{array}{l}\text { Very relevant in considering that the operating } \\
\text { environment of the firm has a moderating } \\
\text { effect on its performance }\end{array}$ \\
\hline
\end{tabular}

Source: Author, 2019. 


\subsection{Conceptual Review}

\subsubsection{Social Capital}

Social networks are the basic elements of social capital as they encompass individuals and social compositions (Dubos, 2017). They thus provide a critical conceptual linkage that can be harnessed towards dynamism and differentiation in economic performance. Woolcock, (2001) argues that social capital provides an avenue for the most efficient combination of the other factors, and hence optimizes output. This led to a fast building consensus among researchers; that indeed social capital plays a pivotal role in economic development, and they sought to answer the many questions arising, such as what exactly is social capital, and what is it not? Is it a homogeneous concept? In what form(s) does social capital exist? The entrepreneurial researcher's particular interest in social capital would be its exceptional features in relation to other types of capital, and how this can be exploited to positively affect entrepreneurial ventures at all levels. With today's increased productivity in a global world, enterprises stand to gain superiority to competition, effective technological use and lead through innovation; all of which reveal social capital of ventures. (Taşdemir, Bahar, \& Çayırağası, 2017)

Social capital renders itself as very prospective in developing and boosting social performance in comparison to other forms of capitals (Coleman, 1988). This potential comes from the premise that the other assets such as physical resources and human resources are limited hence deplete-able, while social capital's efficiency increases with continued exploitation (Park \& Jeon, 2007). Despite lots of literature and research on this nascent concept, though, there seems to be almost as many varied descriptions of the concept as the authors of the subject; with each defining it from their own viewpoint, as observed by Narayan \& Pritchett, (1997). Knowles (2005) played a major role as he summarized some of the most commonly used definitions of social capital as a concept.

For purposes of this study, we will apply social capital as the collective resources accessible by and through interpersonal as well as business connections and relationships. These relationships then generate potent resources for the actors, in form of business prospects, knowledge, financial assets, ideologies, business leads, moral support, reliance, collaboration and benevolence, as per Muniady et al., (2015). The relationship between economics and culture was first explored through the works of Karl Marx (1818-1883), Emile Durkheim (1858-1917), Georg Simmel (1858-1918), John Dewey (1859-1952), as well as Max Weber (1864-1920). Subsequent scholars sought to understand to what extent social capital exhibits properties that resemble other types of capital, and how strong these properties are, to justify the concept. These discussions further led to classification of types of social capital, namely structural and cognitive interactions which entail bonding, bridging, and linking social capital, strong and weak social interactions, as well horizontal and vertical connections.

Svendsen and Svendsen (2005) opine that social capital shares certain characteristics with other forms of capital and, consequently, argue that it ought to be considered a valid form of capital; because just like the physical, economic, and human assets, social capital has the potential to offer instant or delayed benefits to each member of the social network (information or help from friends). The members could thus choose to translate this value of social capital into other applicable forms of capital on a need basis, e.g. when one gets a new business or employment opportunity through their social networks. Benefits could hence be harnessed immediately or in the future.

Social capital varies from other forms of capital in that it has joint ownership; it is co-owned by all the involved parties but may be harnessed differently; some people exploit it more than others. Is social capital always a positive contributor in society? Far from it; like any other form of capital, social capital can be misused. The connections and inter-dependence that allow drug cartels and other illicit crews to thrive could be seen as abused social capital; one that takes advantage of underlying systemic weaknesses such as a malfunctioned societal value system, lack of basic needs among members etc. Has technology driven or suffocated social networks? Social engagement might just be evolving through virtual communities with no physical limitations; people can now enroll in worldwide associations within which members share certain aspects; such as Dyslexic people finding support groups across the globe.

But how strong are the ties in such engagements among people who may have common interests yet operate in completely different environments; some people are not persuaded that these emerging virtual communities may not bear the same or more value as the traditional networks. Effect of technology on social engagement, and the (un) realness of the members compared to traditional forms, is therefore an area requiring further research. The richness or actual value of social capital is largely determined by the magnitude of one's social network, as well as the amount of capital whether economic or cultural, that belongs to the members within the said networks. In corporate entrepreneurship, social capital plays a major role towards availing capital to ventures, because the 
formal and unofficial networks will help entrepreneurs access more than finances; they will access knowledge, market insights, current investment opportunities and future trends, as observed by Alexy, Block, Sandner and Wal, (2012).

Social capital consists of three dimensions i.e. structural, relational and cognitive. The study will consider the structures, trusts and cognition as some key constructs of Social interactions (Parra-Requena, Ruiz-Ortega, \& García-Villaverde, 2011); and from these elements, this study will derive the hypothesis when measuring the effect of an entrepreneur's social capital on their own business. It further seeks to establish the presence or lack of it thereof, of ties amongst the connectors. Benefits accrued from connecting to large numbers of people include access to more information, at a faster rate, and the likelihood of diversity in the connections (Smith et. al., 2005). It is from these theoretical arguments that two possible hypothesis for this study will be extracted; that the number of people with whom an entrepreneur connects has a positive effect on the business performance, and that the diversity of the entrepreneur's connections has a positive influence on the performance of his business.

\subsubsection{Firm Performance}

Classical economists identified the basic factors of production that lead to the growth of an economy as land, labor and financial capital. Solow (1957) first considered technology as an integral part of physical capital, and which was an equally important factor in economic growth. Other neo-classical economists led by Becker (1964) and Schultz (1981) introduced the concept of human capital. They posed that education, training, as well as the health of workers were key determinants of productivity, and which interplay with the traditional factors of production. This increased efficiency and value of social capital will then catalyze business performance for any entrepreneur who taps into it. It is for the same reason that highly performing firms are able to achieve low transaction costs; due to high levels of trust, knowledge sharing among members and the mutually beneficial strength of collaboration among them.

Venkatraman and Ramanujam's (1986) framework for measuring performance depicts several indicators of firm performance as financial and operational performance as well as overall effectiveness of the firm. Financial performance seeks to measure the overall profitability, and is often presented inform of ratios e.g. return on investment, return on sales, return on assets, and return on equity, or by profit margins, per share earnings, the firm's stock price and by growth of sales. On the other hand operational performance considers the non-financial aspects, and points to operational success factors that have the potential to lead to financial performance. Operational performance encompasses product-market outcomes such as the firm's market share, their efficiency, introduction of new products to the market, innovation levels, and the product or service quality offered by the firm.

Operational performance further considers the output of internal process such as staff productivity, employee retention rate and employee satisfaction, as well as turn-around time. A measure of overall effectiveness reveals a much deeper review of performance and considers the firm's reputation, survival tactics, the real or perceived overall performance and achievement of pre-set goals in as compared to the firm's competitors (Lewin \& Minton, 1986; Venkatraman \& Ramanujam, 1986). In the past two decades, social performance has immensely grown as a consideration for firm performance; over fifty percent of the fortune 1000 companies in USA have incorporated corporate social responsibility (CSR) within their annual reports. According to Wenhao and Kaufman (2011), 48 out of the top Fortune 50 in USA articulated their Corporate Social Responsibility (CSR) activities in their websites, and some even had dedicated websites on CSR.

Further, a study carried out on Fortune 1000 companies established that there was an incredibly strong relationship between a firm's social responsibility, their profitability and the firm's social standing (Bonner \& Friedman, 2012). Firms in Kenya too, spend huge sums of money on social performance with thriving programs such as Wings to Fly by Equity Bank 9Kenya) in collaboration with MasterCard Foundation, Mpesa Foundation Academy by Safaricom (Kenya), and the Annual Mater Heart Run by Mater Hospital(Kenya) among others. These have seen the firms gain repute and mileage among Kenyans and beyond. In the small businesses arena, though, some ventures have embraced CSR while some managers resist, possibly due to their 'limited' resources, as they contend that CSR is a heavy investment that conflicts with their endeavors towards maximizing profits (McGuire, Sundgren \& Schneeweis, 1998).

For this study, firm performance will be measured using financial and non-financial parameters. Given that most early-stage and informal entrepreneurs may not have their financial books very well organized, and for some these may not exist, we will consider financial parameters in terms of (perceived) business growth in form of sales, increase in number of employees and number of (new) branches opened to-date. Non-financial measures will include customer satisfaction (repeat customers), and social performance which will seek to establish the 
extent of involvement of the venture in social responsibility activities within the community.

\subsubsection{Innovation}

Entrepreneurs especially those in small businesses tend to operate on limited resources. In such circumstances where the venture is faced with challenges of limitation in resources, innovation becomes extremely critical for the venture; if merely as the survival strategy. Wolff and Pett (2006) argue that dexterity and innovation are some of the best ways through which a firm can internally compensate for their deficit in resources. Ironically, the small businesses often ignore research and innovation, assuming it is a reserve of the established and resource-endowed firms. Innovation is therefore not a factor of the assets the firm has to its name, but a deliberate effort and purposeful culture of the venture.

Today, several firms that have remained outstanding in innovative excellence, e.g. Google, Facebook, and Amazon, among others, consciously and continuously choose to focus on innovation networks to drive their innovation agenda, rather than wait upon a few innovative geniuses. Such knowledge networks are gaining popularity due to their ability to synergize varied competencies and enhance organizations' learning and knowledge sharing. Due to this organizational gain, companies are increasingly creating such channels where people with different competencies can congregate with innovation being the agenda. Google Cafés are an example of such a setting; intentionally designed to encourage interactions between employees and cross-functional teams, and subsequently, to spur innovations, as noted by Bloch (1999).

In corroboration of this argument, there is immense previous research which suggests that a firm's innovation performance is heavily dependent on how entrenched the firm's culture is in ensuring an environment conducive for innovation, as observed by Longo (2017). Initially, indicators of innovation were grouped into five that is new products, new processes, new raw materials and assets, new markets and new forms of organization. These were then condensed into two major categories namely product and process innovation (Brouwer, 1991). To measure innovation, this study will consider the level of Product / Service Innovation and Process innovation within the venture.

\subsubsection{Operating Business Environment}

Internally, businesses are often faced with lack of resources, especially tangible assets. Externally, the enterprise has to confront various environmental turbulences such competitors, changing needs of customers and fast changing technology, among others. Firms with higher social capital (SC) are better placed to achieve their objectives under low environmental turbulence. Under high environmental turbulence, nonetheless, social capital has been found to contribute positively towards the firm's performance (Tang et al., 2010; Chawla et al., 2012).Despite of and in addition to the challenge of limited resources, ventures must thus strive for flexibility that will allow them to respond to the anticipated and unforeseen environmental instability (Nunéz \& Lynn, 2012; Coad et al., 2013).

In order to seize the business opportunity in spite of their limited resources, business enterprises often look up to social capital to help manage the challenge of high transaction costs (Clopton, 2011). They will either lobby towards reduction of operating costs, or acquire upstream and downstream services within their supply chain. Lobbying as a solution for common entrepreneurial challenges or aimed at developing the venture environmental factors requires that networking be applied through consensus and co-operation among members within the same organization or the industry. This therefore suggests that social capital too, can be tapped by the firm as a strategy for addressing certain environmental turbulences.

This study thus seeks to determine to what extent environmental turbulence (ET) moderates the impact of social capital and innovation on firm performance. Environmental turbulence (ET) comes with both opportunities and threats for the firm, depending on how the entrepreneur reacts to it. Ventures with greater entrepreneurial management often adopt informal systems and may thus benefit more from environmental instability (Didonet, Simmons, Villavicencio, \& Palmer, 2012). Enterprises that have standardized their processes and centralized their operations are better placed to increase their efficiency during moments of low environmental instability. However, periods of increased turbulence often tend to trigger inefficiency in such centralized firm structures (Chi \& Shun, 2013). In this study, a firm's external operating environment will be considered in the form of technological turbulence, market turbulence, as well as competition turbulence.

\subsection{Social Capital and Firm Performance}

The effect of social capital on performance has been extensively studied at various levels, cutting across all ranges i.e. the individual, informal as well as small groups (Behrens, \& Krackhardt, 2000) extending to organized and random communities as well as nations (Putnam, 1995). Broadly, social capital has been found to 
yield positive influence on organizational performance (Andrew, 2010). Prior studies have discussed two major means through which social capital affects organizational performance; namely trust and presence of social networks. Trust provides an environment conducive for participation in knowledge and information sharing (Kim \& Lee, 2000), while presence of networks facilitates development and sharing of intellectual assets through knowledge and information sharing as well as peer education (Krackhardt, 1992; Burt (1997). Informed by these previous works, this study considers the entrepreneurs' networks in assessing the relationship between social capital and firm performance.

Wirba et al. (2017) carried out an exploratory research on social capital and SME performance. From the research, it was concluded that social capital plays a key role within SMEs to achieve their business goals. Additionally, it was pointed out that social capital has a substantive relationship with performance of SMEs. Consequently, this research endorses that SMEs undertake a preemptive attitude to encourage, construct and uphold viable social networks in order to develop higher profit from it. Suggested future research areas include the need to scrutinize the magnitude of effect exerted by the factors of social capital on SMEs performance. The research gaps identified include contextual gaps in that the research needs to be carried out in other countries and contexts, in order to ascertain if the outcome will be consistent.

Obonyo (2017) studied social capital and the growth of medium enterprises in Kenya; the objective was to establish the effect of social capital on the growth of medium enterprises in the service sector in Kisumu City, Kenya. Descriptive correlation design was used. A structured questionnaire was adopted for data collection. Key weaknesses identified include the use of descriptive design which is known to be the weakest design when seeking to determine predicted cause and effect relationships. Additionally, the research used direct relationship in that there were no moderating or mediating variables applied in the study. The benefits of incorporating mediating variables cannot be underestimated (MacKinnon \& Luecken, 2011) as they help improve the measurement of variables as well as improve the theories.

Moderator variables, too, are known to alter the strength of the connection between an independent and dependent variables. Use of moderating variables dates far back and remains significant history in diverse research fields (Aguinis, 2004). Failing to incorporate moderating variable, therefore, may yield inaccurate results given that businesses do not operate in a vacuum. Further, the use of structured questionnaires only has been found to limit the respondents thus failure to obtain further and objective insights from the respondents. Song (2016) studied the effect of social capital on organizational performance in different cultures namely United States and Korea. The study employed survey data from only two small cities, hence the findings may not be representative of the larger cities or other diverse cultures. Additionally, Kiprotich (2014) studied the influence of social capital on the growth of SMEs operating in Nairobi County. The study applied a descriptive research design, and the population was all SME's operating in the Nairobi Business District. Questionnaires were the tool used to collect data. The study findings were that social capital affects the growth of SME's.

The nature of the relationships, however, differed with every growth indicator and every social capital variable. The author thus proposed that further research be undertaken with a view to comprehend why culture and civic engagement variables reveal negative effects on SME growth. Further proposal is that a thesis be developed and tested to better understand the relationship. There exists, therefore, knowledge and empirical gaps in that the study was not conclusive due to the scope of this particular study; it points out pertinent areas for further research.

\subsection{Emerging issues from Literature Review}

Tantardini and Kroll (2015) argue that organizational social capital is a vital tool for performance management, yet it is also one of the most disregarded. Previous studies such as Ismail et. al., (2014) and Subrahmanya (2011), have studied the linkage between social capital and firm performance among established business settings such as manufacturing, auto and electronics firms respectively, hence there is need to focus on the less formal businesses which are characterized by limited resources and non-documented measures of performance. Other studies conducted by Kiprotich (2014) studied social capital and growth of SMEs in Nairobi County, Obonyo (2017) (social capital and growth of SMEs in Kenya) and Mbizi et al., (2013) have all applied descriptive design, which has been known to be the weakest in studies that seek to test predictions on cause and effect relationships among variables; descriptive design largely describes variables rather than test the relationship between the variables.

Additionally, Obonyo (2017) studied the direct relationship but did not consider any mediating or moderating variables. Given that businesses do not exist in a vacuum, downplaying or failing to consider the moderating and mediating variables is likely to yield inaccurate or weak findings. Some authors such as Rosli and Sidek (2013) 
have studied the mediating effect of innovation on the performance of SMEs in Malaysia, Ismail et al. (2014) studied the role of innovation on SMEs in the manufacturing and service sectors in Malaysia. Others such as Pratono and Mahmood (2016) studied the entrepreneurial ecosystem and sought to establish the moderating effect of environmental turbulence and mediating effect of market capability in the connection between entrepreneurial orientation (EO) and firm performance. None so far, however, have studied the combination of innovation and operating business environment as mediating and moderating effects respectively, on social capital and firm performance.

Literature review reveals that obtaining financial data from privately owned ventures is quite difficult due to the unavailability of any publicly declared and objective reports (Priem et al., 1995; Sapienza et al., 1988). The reviewed studies focusing on social capital and firm performance have focused on small businesses yet did not consider the subjective measures of firm performance as recommended.

\section{Proposed Conceptual Framework}

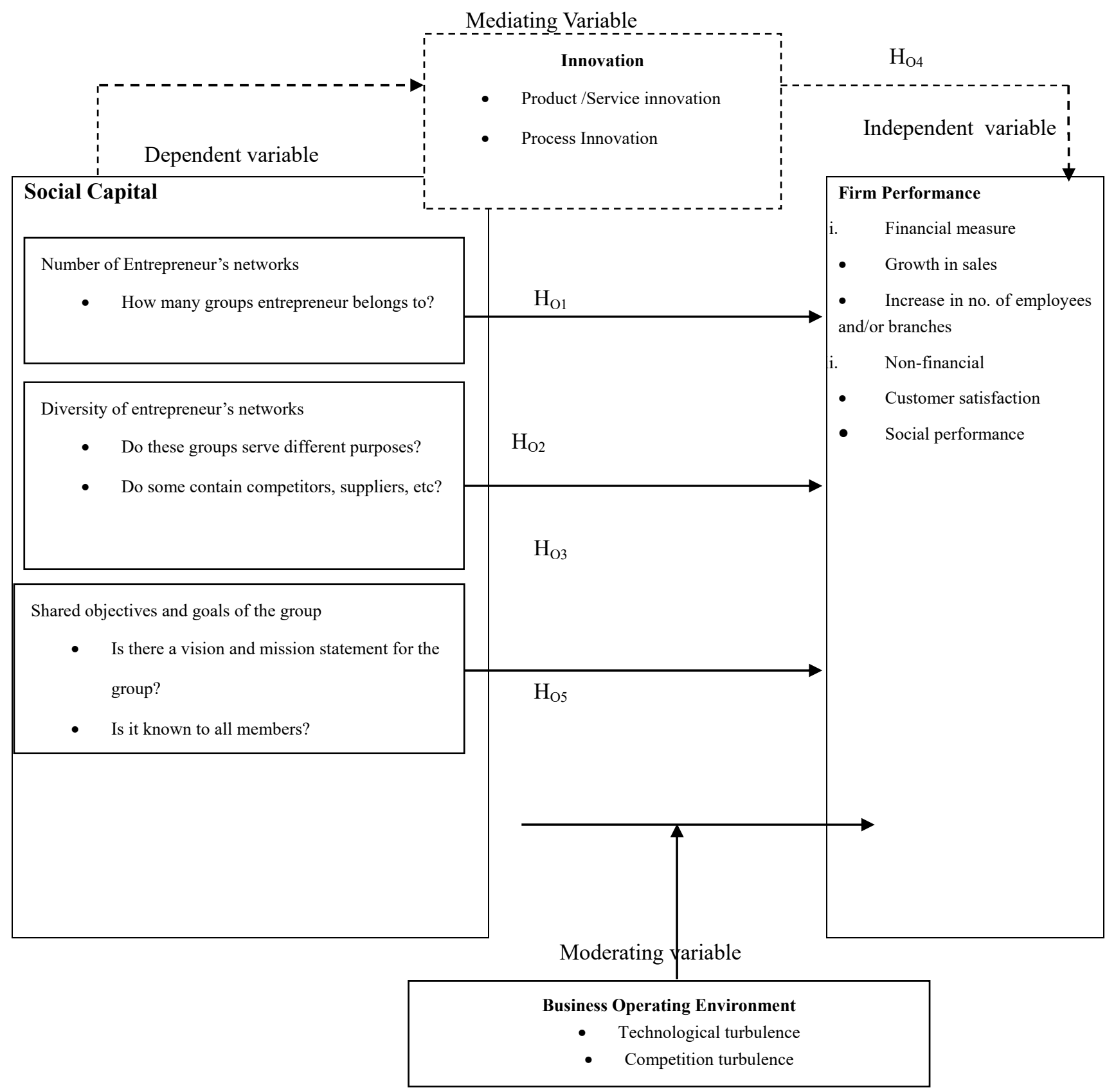

Figure 1. Conceptual Framework 


\subsection{Prepositions}

The above framework represents the proposed study relationship between the aspects of social capital and performance, while factoring in the mediating variable of innovation, and the moderating variable namely operating environment. Social capital is the Independent variable while performance is the dependent variable whose outcome depends on social capital. The hypotheses that can be drawn from the above conceptual framework are:

$\mathrm{H}_{\mathrm{O} 1}$ : The number of Entrepreneur's social networks has no significant effect on Firm Performance.

$\mathrm{H}_{\mathrm{O} 2}$ : The diversity of Entrepreneur's social networks has no significant effect on Firm Performance.

$\mathrm{H}_{\mathrm{O} 3}$ : Presence of shared objectives and goals within the entrepreneur's networks has no significant effect on Firm Performance.

$\mathrm{H}_{\mathrm{O} 4}$ : There is no significant mediating effect of Innovation on the relationship between Social Capital and Firm Performance.

$\mathrm{H}_{\mathrm{O} 5}$ : There is no significant moderating effect of Operating Business environment on the relationship between Social Capital and Firm Performance.

\subsection{Conclusion and Direction for Future Research}

Based on the extensive review and gaps identified, this study proposes to carry out further research among small businesses in Kenya, and particularly in a setting where entrepreneurs have limited resources as well as non-published financial measures of venture performance.

\subsubsection{Proposed Methodology}

It is proposed that the study employs both explanatory none experimental and descriptive cross-sectional research designs. Cooper and Schindler (2008) posit that descriptive design enables a researcher to adequately observe the uniqueness of their study population, and consequently test the study hypothesis. Nassaji (2015) highlights that qualitative descriptive approach is best suited for describing elements and their characteristics especially because the researcher would have no control over the variables. Oppong (2013) emphasizes the need to ascertain that sample size applied in a particular research is sufficient and representational.

Some studies that were reviewed also used very small sample sizes; hence this study proposes to scientifically determine a representative sample size. An appropriate and representative sample will thus be derived after establishing the population. The appropriate data collection tools would be both questionnaires as well as interviews. The questionnaires would have both structured and semi-structured questions to enable the researcher gain detailed information from the respondents, which was missing in some of the reviewed studies that solely relied on structured questions.

\subsubsection{Contextual Proposition}

From the extensive review, the study concludes that there is a relationship between social capital and performance. Contextual gaps have been identified in that research has been carried out among more established business settings. Consequently, this study recommends that a study be carried out among small businesses in Kenya; preferably among low income business areas.

\section{References}

Aghion, P., \& Howitt, P. (1992). A Model of Growth through Creative Destruction. Econometrica, Econometric Society, 60(2), 323-351.

Aguinis, H. (2004). Regression Analysis for Categorical Moderators. New York: Guilford.

Ahuja, G. (2000). Collaboration Networks, Structural Holes, and Innovation: A Longitudinal Study. Administrative Science Quarterly, 45(3), 425-455.

Baron, R., \& Kenny, D., (1986). The moderator-mediator variable distinction in social psychological research: conceptual, strategic, and statistic considerations. J. Personality Soc. Psychol, 51(6), 1173-1182.

Becker, G. (1964). Human Capital. Princeton, N.J. Princeton University Press.

Björk, J. C. (2011). Analyzing and Realizing Collective Ideation in Firms. PhD Thesis, Chalmers University of Technology, Department of Technology Management and Economics, Gothenburg.

Björk, J., \& Magnusson, M. (2009). Where do Good Innovation Ideas Come From? Exploring the Influence of Network Connectivity on Innovation Idea Quality. Innovation Management, 662-670. 
Bloch, M. (1994). Man, 29(2), 487-488. https://doi.org/10.2307/2804509

Burt, R. S. (1992). Structural Holes: The Social Structure of Competition. University of Illinois at Urbana-Champaign's Academy for Entrepreneurial Leadership Historical Research Reference in Entrepreneurship.

Burt, R. S. (1997). The Contingent Value of Social Capital. Administrative Science Quarterly. 42(2).

Chi, T., \& Shun, Y. (2013). Development of firm export market oriented behavior: Evidence from an emerging economy. International Business Review, 22(1), 339-350. https://doi.org/10.1016/j.ibusrev.2012.05.003

Chung, H., Wang, C., \& Huang, P. H. (2012). A contingency approach to international marketing strategy and decision-making structure among exporting firms. Int. Mark. Rev., 29(1), 54-87.

Clopton, A. (2011). Social capital and team performance. Team Performance Management, 17(8), 369-381.

Coleman, J. (1988). Social Capital in the Creation of Human Capital. American Journal of Sociology, 94, S95-S120

Didonet, S., Simmons, G., Villavicencio, G., \& Palmer, M. (2012). The relationship between small business market orientation and environmental uncertainty. Marketing Intelligence \& Planning, 30(7), 757-779.

Dubos, R. (2001). Social Capital. New York: Routledge. https://doi.org/10.4324/9781315129457

Favell, A., (1993). James Coleman: Social Theorist and Moral Philosopher?. American Journal of Sociology Amer J Sociol, 99. https://doi.org/10.1086/230317

Government of Kenya. (2005). Sessional paper no. 2 of 2005 on development of micro and small enterprises for wealth and employment creation for poverty reduction. Nairobi: Govt. Printer.

Government of Kenya. (2014). Sessional paper no. 2 of 2014 on social protection policy. Nairobi: Govt. Printer.

Granovetter, M.S., (1985) Economic Action and Social Structure - the problem of embededness. American Journal of Sociology, 78(6), 1360-80.

Gupta, S., \& Malhotra, N. (2013). Marketing innovation: A resource-based view of international and local firms. Marketing Intelligence \& Planning, 31(2), 111-126.

Hofstede, G. (1980). Culture's consequences. Beverly Hills, Calif.: Sage Publications.

Jacobs, J. (1961). The Death and Life of Great American Cities.

Kim, W. B., \& Lee, K. Y. (2000). Trust as Social Capital and Organizational Commitment Korean Sociological Association.

Kiprotich, E. (2014). The influence of social capital on the growth of SMES in Nairobi County, Kenya.

Krackhardt, D. (1992). The Strength of Strong Ties. In Nohria, N., \& Eccles, R. G. (Eds.), Networks and Organizations: Structure, Form and Action. Boston: Harvard Business School Press. Pp. 216-239.

Longo, M. C., Narduzzo, A. (2017) Transactive knowledge from communities of practice to firms: An empirical investigation of innovative projects performance. Eur. J. Innov. Manag., 20, 291-311.

MacKinnon, D. P., Luecken L. J., (2011). Statistical analysis for identifying mediating mechanisms in public health dentistry interventions. Journal of Public Health Dentistry, 71, S37-S46.

Mahr, D., Lievens, A., \& Blazevic, V. (2014). The value of customer co-created knowledge during the innovation process. J. Prod. Innov. Manag, 31, 599-615.

McGuire, J. B., Sundgren, A., \& Schneeweis, T. (1988) Corporate social responsibility and firm financial performance. Academy of Management Journal, 31(4), 854-872.

Muniady, R. A., Mamun, A. A., Mohamad, M. R., Permarupan, P. Y., \& Zainol, N. R. B. (2015). The Effect of Cognitive and Relational Social Capital on Structural Social Capital and Micro-Enterprise Performance. SAGE Open, 5(4), 1-9. http://doi.org/10.1177/2158244015611187

Narayan, D., \& Pritchett, L. (1997). Cents and Sociability: Household Income and Social Capital in Rural Tanzania. Washington, DC: World Bank.

Obonyo R. O. (2017). The Effect of Social Capital on the Growth of Medium Enterprises in Kenya.

Penrose, E. (1959). The Theory of the Growth of the Firm. Oxford, UK: Oxford University Press.

Pratono, A. H., \& Mahmood, R. (2016). Social Capital and Firm Performance: Moderating Effect of 
Environmental Turbulence. Asian Social Science.

Putnam R. D. (1993). The Prosperous Community: Social Capital and Public Life. The American of Prospect, 13, $35-42$.

Rice, T. (2001). Social Capital and Government Performance in Iowa communities. Journal of Urban Affairs, 23, 375-390.

Rowley, T., Behrens, D., \& Krackhardt, D., (2000). Redundant governance structures: An analysis of structural and relational embeddedness in the steel and semiconductor industries. Strategic Management Journal.

Schultz, T. W. (1961). Investment in Human Capital. The American Economic Review, 8(1), 1-17. Retrieved from http://www.jstor.org/stable/1818907

Schulz, T. W. (1981). Investing in People: The Economics of Population Quality. Berkeley. University of California Press.

Sciascia, S., Mazzola, P., \& Chirico, F. (2012). Generation involvement in the top management team of family firms: Exploring nonlinear effect on entrepreneurial orientation. Entrepreneurship Theory and Practice, 37(1), 69-85. http://dx.doi.org/10.1111/j.1540-6520.2012.00528.x

Solow, R. (2000). Notes on Social Capital and Economic Performance. In Partha Dasgupta and Ismail Serageldin (Eds.), Social Capital: A Multifaceted Perspective. Washington, D.C.: World Bank.

Song, J. H. (2016). The Effect of Social Capital on Organizational Performance in Different Cultures: A Cross-National Comparison of the United States and South Korea. FIU Electronic Theses and Dissertations, 2613. http://digitalcommons.fiu.edu/etd/2613

Tantardini, M., \& Kroll, A. (2015). The Role of Organizational Social Capital in Performance Management, Public Performance \& Management Review, 39(1), 83-99. http://doi.org/10.1080/15309576.2016.1071163

Taşdemir, D., Bahar, A. D., \& Çayırağası, F. (2017). A Study on Social Capital Concept, Development and Importance. International Journal of Management Science and Business Administration, 4(1), 52-56.

Venkatraman, N., \& Ramanujam, V. (1986). Measurement of Business Performance in Strategy Research: A comparison of approaches. Academy of Management Review, 11(4), 801-814.

Wirba, A., Hoq, M. Z., \& Baig, A. (2017). Social Capital and Small Medium Enterprise (SME) Performance: An Exploratory Study. International Journal of Novel Research in Marketing Management and Economics, 4, 33-39.

Wolff, J., \& Pett, T. L. (2006). Small-Firm Performance: Modeling the Role of Product and Process Improvements. Journal of Small Business Management, 44(2), 268-284 2006.

Woolcock, M. (1998). Social Capital and Economic Development: Toward a Theoretical Synthesis and Policy Framework. Theory \& Society, 27(2), 151-208.

Woolcock, M. (2001). The Place of Social Capital in Understanding Social and Economic Outcomes. Paper Presented at the Contribution of Human and Social Capital to Sustained Economic Growth and Well-Being, Ottawa.

World Bank. (2011). What is social capital? Retrieved from http://go.worldbank.org/K4LUMW43B0

\section{Copyrights}

Copyright for this article is retained by the author(s), with first publication rights granted to the journal.

This is an open-access article distributed under the terms and conditions of the Creative Commons Attribution license (http://creativecommons.org/licenses/by/4.0/). 